\title{
Integration Precision and Unmanned Aerial Vehicles Technology in Oil Palm Management System Development
}

\author{
Kai Chen Goh, Sy Yi Sim, Toong Hai Sam, Kamalludin Bilal, Hui Hwang Goh, Sulzakimin \\ Mohamed
}

\begin{abstract}
Agriculture industry stakeholders, especially those in oil palm industry, reckon the significance of pursuing sustainability due the competitiveness in the industry. Moreover, rigorous requirements which imposed by sustainable organizations and authorities has given rise to the industry stakeholders for continually seeking for better solutions to minimize the total operating cost. Yet even though these scenarios are what satisfies and act as the market drive to promote the research in precision technologies, the practices of precision technologies in Malaysia's oil palm industries still lack in its pace. This research aims to develop a sustainable precision agriculture management system for the oil palm industry. The research then moved forward to the development of Oil Palm Management System (OPAMS) which serves as a monitoring and data management system to justify the decision making in oil palm plantation operational process to achieve sustainable goal. The system assists them in monitoring, control and properly manages their resources, including fertilizers, chemical, pesticides, energy and water with better efficiency. The research raised the awareness of precision agriculture practices in oil palm industry, allow industry stakeholders taking sustainability into account while making operating investment and management decisions.
\end{abstract}

Index Terms: Construction Industry, Awareness, Construction Collaboration Tools, Cloud Computing.

\section{INTRODUCTION}

Drastic changes need to be made in the global food system in order to achieve a more sustainable agriculture that feeds people adequately, contributes to rural development and provides livelihoods to while sustaining the natural resource basis [1]. As the world become more aware, sustainable agriculture slowly replaces the conventional

Revised Manuscript Received on August 18, 2019

Kai Chen Goh, Department of Construction Management, Universiti Tun Hussein Onn Malaysia, Parit Raja, Johor, Malaysia.

Sy Yi Sim, Department of Electrical Engineering Technology, Universiti Tun Hussein Onn Malaysia, Pagoh, Johor, Malaysia

Toong Hai Sam, School of Business, INTI College Nilai, Selangor, Malaysia.

Kamalludin Bilal, Department of Construction Management, Universiti Tun Hussein Onn Malaysia, Parit Raja, Johor, Malaysia.

Hui Hwang Goh, School of Electrical Engineering, Guangxi University, Nanning, Guangxi Province, China.

Sulzakimin Mohamed, Department of Construction Management, Universiti Tun Hussein Onn Malaysia, Parit Raja, Johor, Malaysia. agriculture practice [1,2]. Agriculture industry shows several changes over the decades, as the vastly usage of Remote Sensing (RS) reduced the wastage of fertilizers and pesticides in the industry, it promotes sustainable development of the agriculture industry in a wider context. The application and development of the agriculture industry implies the path towards the sustainable agriculture, and one of the ways to achieve it is by the means of Precision Agriculture (PA). The planters which practice PA gain more productivity in terms of quality control and able to generate more income, while reducing the negative impact on the environment. In the year 2012, World Wide Fund organization made a study and state that the world need to produce more food in the coming 4 decades as compared to 8000 years ago [3]. This is the crisis that the global society has to face, unlike the times before.

The purpose of PA in agriculture industry is to manage the crop production. PA promises a more sustainable form of agriculture that aims to produce food in a more environmental friendly and social way [4-6]. PA thus potentially provides means of addressing both human and environmental predicaments. There is a need to promote the sustainable agriculture, such as PA. One of the reasons is that recent trends in population and per-capita wealth continue, feeding a world population of about 9 billion people in 2050 would require raising aggregate global food production by at least $60-70 \%$. With the benefits of the PA, the crop production can keep up with the growth of the world's population.

The role of PA technologies towards sustainable oil palm management system in Malaysia

PA method is related closely to crop management system, as it is a process of identifying the crops' health, and manage its productivity through the control amount of fertilizers, pesticides, and care. It may help the planters to save time and cost in the process while providing the knowledge of efficiently managing the crops. Crop management system is also related to risk management, resource management and technology management in agriculture. One of the technologies used in the agriculture risk management is the PA by mapping out the risks in the agriculture business [7]. 


\section{LITERATURE REVIEW}

In PA, there are several types of technology can be used which is the satellite, aerial vehicles, and automobiles. Current PA technologies used in Malaysia oil palm industry are:

Aerial spraying application was adopted by Malaysia oil palm industry 10 years ago and this application was monopolized by Systematic Aviation Services Sdn. Bhd. (SAS). Ironically, after ten years of time, the aforesaid company is still the one and only aerial crop spraying application service provider in Malaysia. There are total 7 million hectare of agriculture plantation land area in Malaysia, however, only depending on two units of aerial crops spraying aircrafts under the operation of SAS. Aerial spraying application can be considered the fastest and most efficient solution to treat insect and virus infestation for example bagworm infestation in oil palm plantation. No soil compaction is one of the advantages of aerial spraying application and the application will not be affected by wet soil condition in plantation area. Furthermore, the application will not damage the crops in any given fields. Most importantly, aerial spraying application is operated under the support of variable rate application system with a based guidance which consists of DGPS (Differential Global Positioning System). As far as sustainable oil palm management system is concerned, aerial spray application provides a better control of the usage amount of pesticides, reduce time and labour intensive issues for oil palm industry.

Unmanned Aerial Vehicles (UAVs) or drone is a low cost, light weight and easy to manoeuvre flying device which is possessing the ability for agricultural remote sensing and imagery data acquisition. Compared to satellite remote sensing, drone equipped with visual observing unit such as LiDAR, multispectral and hyperspectral sensor can perform imagery data acquisition with much cheaper cost, higher resolution imagery more flexible in terms of time consuming, safety, flying height and timing of flight. By adopting the drone's technology which integrating with visual observing unit, growers are able to obtain the ground-based data to support the oil palm management decision support systems and the existing sustainable oil palm management system to generate an innovative solution for operational decision making to achieve sustainability. Therefore, as far as sustainable oil palm management system is concerned, the contribution of drone's technology leading Malaysia oil palm industry towards the path of sustainability is significant.

Satellite remote sensing technology was adopted by oil palm industry 15 years ago. It is an effective tool to acquire imagery data about the earth surface at a sizeable coverage. Planting operation which includes manuring, harvesting, pruning and weeding should be conducted daily at oil palm plantation to ensure the efficiency and effectiveness of management process. Satellite remote sensing could provide accurate imagery data information as far as planting operation is concerned [8]. Three main types of satellite remote sensing application used in Malaysia oil palm industry are LANDSAT, SPOT and IKONOS. Sustainability of oil palm management in Malaysia oil palm industry utilizes the application to monitor and acquire the data of land cover classification, tree counting, age estimation, soil mapping, yield estimation, palm census, illegal deforestation, spreading of disease, nutrient deficiency detection, leaf and soil analysis. This is an exquisite application to monitor the progress of oil palm development. The collected data will then being analysed by oil palm data monitoring and management system to justify the decision making in oil palm plantation operational process to achieve sustainable goal.

\section{Methodology}

The system development of in this section aims to achieve the objective of developing an intelligent, easy to manoeuvre drone, integrated with a monitoring and data analysis management system to provide oil palm industry stakeholders to generate an innovative solution for operational decision making to achieve sustainability.

[9] discussed conventional approaches with one-dimensional models, plus driving the models with RS inputs, and performing objective parameterization in an inverse modelling approach. [10] indicated models applicable to three spatial scales: individual plants, whole fields, and whole drainage basins. From [10] statements, the proposed imagery RS in this study is capable to capture the data of individual plants such as oil palm height, NDVI, leaf and soil analysis.

[9] briefly discussed topographic analysis, scaling, and modelling to assess both temporal and spatial variability across landscapes. In separate work, [11] described several geostatistical approaches to quantifying variability of measured yield in spatial and temporal dimensions, and in their combination. It can be seen that the modelling of the framework focuses on the spatial variability, which means that RS application is already focused intensively in early days' research. On the other hand, PA requires simulation of point yields at many places within a field. Thus, not only is there a requirement to accurately simulate the field mean, there is also a requirement to accurately simulate the variation in the field.

Despite of that, spatial soil inputs are particularly difficult to obtain, which has prompted a number of inverse modelling studies to determine best-fit parameters [12]. The studies involved are mostly through the application of satellite RS, thus UAV will be chosen as the application of RS in this study so to provide difference input in this PA studies field. The parameters will be listed and explained in chapter 4 to confirm its suitability of parameter for the YM of oil palm. The processes of the framework model for the PA actually involves physical, chemical, and biological variation in real soils are not always fully represented in models of crop growth and yield. General accuracy issues regarding modelling for PA were discussed by [13], however [14] pointed out that accuracy requirements are as varied as model research objectives. In this study, the accuracy requirements are to be validated during the conduct of simulation of the model. One distinctive feature of simulation methods is that, the model employed is referred to as a computational model. Computational model 
involves statistical analysis, usually by software and the data obtained for the statistical analysis are through the simulation method Simulation methods use "computer software to model the operation of real-world processes, systems, or events" [15]. In the events of modelling simulation method for PA, it is also somewhat the same case.

Designing crop management plans based on models requires four important points to be kept in mind. The first is to describe the system of interest properly, depending on the question to be answered (processes, temporal and spatial scales, constraints and boundaries). The second is to build an adequate experimental plan of simulations aiming at designing crop management plans. The third is the simulation work itself. The fourth is how to deal with the simulation data and analyse the results. This research aims to address application of PA in Malaysia oil palm industry. The research phase the modelling of framework will be discussed in this section.

PA can be classified into two categories, namely 'soft' and 'hard' PA. 'Soft' PA mainly depends on visual observation of crop and soil and management decision based on experience and intuition, rather than statistical and scientific analysis. Whereas 'hard' PA utilizes all modern technologies like GPS, RS, VRT etc [16]. The development of PA technologies are through simulation for the technologies such as GIS, GPS, yield mapping and so on [17]. [18] propose a four-step approach to design cropping systems:

i) Define goals and constraints for the new cropping systems. Constraints may result from soil and climate but also from environmental or economic concerns;

ii) Design cropping systems compatible with the set of constraints;

iii) Evaluate the cropping systems;

iv) Test and transfer the most innovative ones to practitioners.

In this research we focus on the use of simulation models to design and evaluate cropping systems in steps 2 and 3. Step 1 and 4 which requires more in-depth knowledge from professional practitioners are to be addressed in the future by horticulturists researchers, agronomists, and perhaps data scientist in agriculture sector. Following the typology of Malézieux (2012), the goals of agro ecosystem models can be sorted into four groups:

- Models that represent knowledge, concepts and methods for scientists;

- Models as tools for communication;

- Models as tools to manage or run systems (used to design crop management systems);

- Models as tools to assist debate.

Since the PA technologies and the steps and the requirements of the framework modelling are identified, the stage of the designating of the PA focus in this study is as follow:

\section{Stage I}

Conceptual and structural design of the technologies through integration of several hardware and software,

\section{Stage II}

Verify the parameters that would be used in the case study simulation, and listing down the functions and specifications of both soft and hard precision technologies to be used in this studies.

3. Stage III

Perform fieldwork simulation.

In which stage (I) will be debated in this chapter, stage (II) and stage (III) in chapter 5. Simulation tools permit the experimenter to studies processes in ways nature prohibits, because the simulation can be run many times with the values of the parameters modified between runs and the changes in outputs observed (Berends \& Romme, 1999). The model validation steps are generally build, verify, and validate the simulation model in the end, whereby the verification is through virtual or real life simulation [19].

The learning of the new agricultural technology invented in developed countries and its proper modification and application according to the domestic condition is necessary, because this will involve the formulation of simulation model. Nearly hundred research papers generated in last three decades have been critically reviewed to find the status of main six components of PA, i.e., Positioning System, RS, Variable Rate Technology, Crop \& Soil Sensing \& Analysis, Yield Mapping and Information Transmission Protocol.

[20] measured apparent soil electrical conductivity and geographically weighted regression was used to characterize the spatial variation in soil properties, which in turn can be used for soil management. The variable used by [20]. The broadening of the tests will should provide a model that is more suitable for a wider range of users and indicate to what extent the model components are generic and robust [21]. Since the parameters for each of the plantation differs from each other, and the technologies which used to determine each of these parameters are different, therefore serious consideration need to be made before deciding the parameters and types of analysis and data collection tools to be used.

\section{RESULTS OF FINDINGS}

The development of a wisdom based systems for the farming sector has to be focused on Internet of Things including geomatics or 3S (RS, GIS and GPS), sensor technology, Wireless Sensor Network (WSN), Radio-Frequency Identification (RFID) and Cloud Computing. The increased use of geomatics in agriculture is adding to a greener agriculture and greater environmental stewardship while maintaining the economic viability of farming enterprises [22]. The accessible, affordable, interactive crowd sourcing platform for sustainable agriculture would provide a means for sharing information regarding traditional sustainable agricultural methods, techniques, tools, tips, etc. and allow interactivity and offline data entry for consolidating 
information upload. According to [22], the development of such system should meet the following requirements:

i. Robust Models: The characteristic features of agriculture sector such as diversity, complexity spatio-temporal variability, and uncertainties need to be considered during the development of product and services features.

ii. Scalability: The size of farms varies from small to large, and hence the solutions should be scalable. The testing and deployment happen in stages and therefore the architecture should be able to scale up incrementally with lesser overhead.

iii. Affordability: Affordability is the key to success. The cost has to be appropriate with substantial benefits. Standardized platforms, tools, products and services can bring the cost down with increased volumes. Open source platforms, cheap products with good specifications are made possible and available at the market these days, thus the achievable rate is quite high.

iv. Sustainability: The issue of sustainability is vital because of intense economic pressure and fierce global competition.

Based on the defined framework model systems' elements as shown in previous subchapters, the development of OPAMS is performed. Firstly, the design constraint or system limitation has to be identified including the size and weight, computing performance and cost of the software and hardware. The development of the system has to be simplified for the developer to troubleshoot, and user-friendly for the oil palm growers to apply and integrate with their current oil palm management effectively and cost efficiently. As the development of OPAMS involves drone, the development of the UAV framework is important as well. Several items determine the efficiency and the cost of drones such as its frame model, materials, propellers and motors, battery, flight controller, communication system, and its total weight [23].

In order to support Big Data and ease of database administration, both Relational Database Management Systems (RDBMS) and NoSQL database must be adopted.

Thermal imagery and image processing algorithm -The software automation methodology for imagery processing is followed by such process: image was captured first, then converted into pixel values, stored in the automatic graph formatting, applied regression calculation algorithm and lastly provide correlation [24]. However such imagery processing still requires the user to understand several items, such as what does RGB stands for in their regression model, or sometimes even black and white value [25]. This research deploys a simpler methodology by utilizing open source data imagery processing during this development stage, which is by the OpenCV, a computer vision cloud platform developed by Microsoft.
Thermal imagery and image processing algorithm are part of machine vision discipline [26]. OPAMS will conduct inspection on the oil palm trees through visual inspection and stored the data in the form of Video footage. Then the system will analyse the video footage using the OpenCV. The hardware camera which is the Raspberry Pi camera module is used to capture high-definition video, as well as still photographs.

The video taken over the air is used to generate a $2 \mathrm{D}$ map of the area using MATLAB, overlaying two maps made at different times which can be useful to trace changes that have taken place in the area [27]. This feature then integrates with the GPS feature to develop a simple mapping for the user to refer to on the coordination of each tree for the purpose of accuracy. In addition the video footage is able to use for analysis of the oil palm trees as well.

The camera, GPS antenna and battery are part of components which formulate the drone hardware together with Raspberry Pi zero as the "brain" of the drone. And the Raspberry Pi zero sends out signal to the transceiver, in this case a computer or laptop pre-programmed with feature to analyse the imagery data acquired from OPAMS inspection activity.

Affordability is the key to success. The cost has to be appropriate with substantial benefits. Standardized platforms, tools, products and services can bring the cost down with increased volumes. Open source platforms, cheap products with good specifications are made possible and available at the market these days, thus the achievable rate is quite high. The oil palm planters' perspective is confined in only economic aspect, rather than areas such as further developing the PA technology applications for data acquisition, analysis and decision making for environmental sustainability. One of the main reason is they still have not encountered the adversity that will raise their awareness to have the need of PA application in their business. This is supported by one of the studies in regard to adversity triggers resilient and sustains their business [28].

Fruit maturity grading system - The palm oil fruit maturity grading system using computer vision technique is presented in this research. The palm oil fruit bunch images are categorized into three classes which are under-ripe, ripe and unripe. A palm oil fruit is said to be ripen when the monocarp colour is reddish orange and the bunch has 10 or more empty sockets of detached fruitless. A research on oil palm fruit bunch was conducted using a digital camera under direct sunlight. In developing the machine vision grading system for the fruit bunch, the palm oil fruit bunch image has to be processed using image processing methods, which are the combination of colour intensities, and filtering technique to cluster the pixels with red colour [29]. In this research studies, the simulation of grading system is developed by using MATLAB software. The process is divided into three parts, which are image acquisition, image analysis and feature extraction, and decision making.

The result from this research shows that the accuracy of this system is $91 \%$. Overall, the research methodology on the fruit maturity grading system shows successful in classifying the palm oil fruit bunch. Added to this, an artificial 
intelligence system is commonly used with the colour vision system to classify the oil palm Fresh Fruit Bunch or known as FFB [30]. Another common colour vision system is the assessment using RGB space which known as Red, Green and Blue spectral analysis on the captured image. RGB is the most common and basic foundation for imagery analysis in the agriculture plantations.

\section{Conclusion}

Overall, this research provides a view of oil palm industry at this moment is lacking of a system and technical know-how for data analysis, interpretation and imagery data acquisition. The industry needs a precise crop management system and data analysis, so that the agriculture industry is able to enable the growers to monitor, control and properly manage their resources especially in fertilizer distribution and detect pathogens, and finally, the improvements in crop yields. The OPAMS development have provided a distinguish reference that the development of oil palm management system for Malaysia oil palm industry is viable. The rigorous requirements imposed by sustainable organizations and authorities have given rise to the industry stakeholders to seek for a more efficient and cost effective system to achieve the goal of sustainability. There is an important question to be answered, 'How to ensure plantation operating process and as well as decision making on the usage and quantity of fertilizers, pesticides, water, energy and labour resources are economically feasible, socially viable and environmentally responsible as far as sustainability is concerned?' The answer to this question is, the implementation of OPAMS or other similar system to achieve the aforesaid object is inevitable. The enormous proof of evidence converged from previous chapters provided an impenetrable manifestation of the validity of OPAMS. The development of OPAMS is able to achieve the objects of this research and ensure the oil palm operating process and control of all the resources are economically feasible, socially viable and environmentally responsible.

\section{ACKNOWLEDGEMENTS}

The authors express gratefully acknowledgment to the industry stakeholders for their valuable contributions towards the success of this research. This research is fully funded by Universiti Tun Hussein Onn Malaysia (UTHM) under Vot: U913, Tier 1 Grant Scheme, Vot: H257, Tier 1 Grant Scheme and U887, Tier 1 Grant Scheme

\section{REFERENCES}

1. Titus, O. B., \& Adefisayo, B. A. (2012). Institutional and Technical Factors Influencing Sustainable Agricultural Practices in Nigeria. International Journal of Science and Technology, 1(11), 609-621.

2. Omorogiuwa, O., Zivkovic, J., \& Ademoh, F. (2014). the Role of Agriculture in the Economic Development of Nigeria. European Scientific Journal, 10(4), 1857-7881.

3. World Wide Fund (UK). (2013). A 2020 vision for the global food system.

4. Comparetti, A. (2015). Precision Agriculture : Past, Present and Future, (SEPTEMBER 2011).
5. Moura, E. G., Sena, V. G. L., Corrêa, M. S., \& Aguiar, A. D. C. F. (2013). The importance of an alternative for sustainability of agriculture around the periphery of the Amazon rainforest. Recent Patents on Food, Nutrition \& Agriculture, 5(1), 70-78. http://doi.org/10.2174/2212798411305010011

6. Yadav, R. (2015). Big Data Meets Small Sensors in Precision Agriculture. International Journal of Computer Applications, 1-4.

7. Powers, L. A., Building, C. E. B., \& Dillon, C. R. (2003). Risk Management in Precision Agriculture Authors : Alabama.

8. Chong, K. L., Kanniah, K. D., Pohl, C., \& Tan, K. P. (2017). A review of remote sensing applications for oil palm studies. Geo-Spatial Information Science, 20(2), 184-200. http://doi.org/10.1080/10095020.2017.1337317

9. Patil, V. C., Al-Gaadi, K. A., Biradar, D. P., \& Rangaswamy, M. (2012). Internet of Things (Iot) and Cloud Computing for Agriculture: an Overview. Agro-Informatics and Precision Agriculture, (i), 292-296.

10. Kiniry, J. R., Macdonald, J. D., Kemanian, A. R., Watson, B., Putz, G., \& Prepas, E. E. (2008). Plant growth simulation for landscape-scale hydrological modelling. Hydrological Sciences Journal, 53(5), 1030-1042. http://doi.org/10.1623/hysj.53.5.1030

11. Spyros, F., Søren, M. P., \& Simon, B. (2005). ICT in Precision Agriculture-diffusion of technology. Greece: University of Thessaly.

12. Ferreyra, R. A., Jones, J. W., \& Graham, W. D. (2006). Parameterizing spatial crop models with inverse modeling: Sources of error and unexpected results. Transactions of the Asabe, 49(5), 1547-1561.

13. Sadler, E. J., Jones, J. W., Sudduth, K. A., \& Stafford, J. V. (2007). Modeling for precision agriculture : how good is good enough, and how can we tell ? Precision agriculture'07, 241-248.

14. Sargent, R. (2009). Verification and validation of simulation models. Proceedings of the 2009 Winter Simulation Conference, 37, 162-176. http://doi.org/10.1109/EMR.2009.5235461

15. DeLonge, M. S., Miles, A., \& Carlisle, L. (2016). Investing in the transition to sustainable agriculture. Environmental Science and Policy, 55, 266-273. http://doi.org/10.1016/j.envsci.2015.09.013

16. Shanwad, U. K., Patil, V. C., \& Gowda, H. H. (2004). Precision Farming: Dreams and Realities for Indian Agriculture. In Map India Conference (p. 15).

17. Hakojärvi, M., Hautala, M., Ahokas, J., Oksanen, T., \& Maksimow, T. (2010). Platform for simulation of automated crop production. Agronomy Research, 8(1), 797-806.

18. Goh, K. C., Sim, S. Y., Goh, H. H., Bilal, K., Sam, T. H., Teoh, T. Y., \& Tey, J. S. (2018). Evolution of precision agriculture computing towards sustainable oil palm industry. Indonesian Journal of Electrical Engineering and Computer Science, 11(2), 725-732. doi:10.11591/ijeecs.v11.i2.pp725-732

19. Koch, B., \& Khosla, R. (2003). The Role of Precision Agriculture in Cropping Systems. Journal of Crop Production, 9(1-2), 361-381.

20. http://doi.org/10.1300/J144v09n01_02

21. Terrón, J. M., da Silva, J. R. M., Moral, F. J., \& García-Ferrer, A. (2011). Soil apparent electrical conductivity and geographically weighted regression for mapping soil. Precision Agriculture, 12(5), 750-761. http://doi.org/10.1007/s11119-011-9218-5.

22. Huth, N. I., Banabas, M., Nelson, P. N., \& Webb, M. (2014). Development of an oil palm cropping systems model: Lessons learned and future directions. Environmental Modelling \& Software, 62, 411-419. http://doi.org/10.1016/j.envsoft.2014.06.021

23. Patil, V. C., Al-Gaadi, K. A., Biradar, D. P., \& Rangaswamy, M. (2012). Internet of Things (Iot) and Cloud Computing for Agriculture: an Overview. Agro-Informatics and Precision Agriculture, (i), 292-296.

24. AbdElHamid, A., Zong, P., \& AbdElHamid, B. (2015). Advanced software ground station and UAV development for NLoS control using mobile communications. Discrete Dynamics in Nature and Society, 2015. http://doi.org/10.1155/2015/285746

25. Ismail, W. I. W., \& Razali, M. H. (2010). Outdoor Colour Recognition System for Oil Palm Fresh Fruit Bunches (Ffb). International Journal of Machine Intelligence, 2(1), 1-10. http://doi.org/10.9735/0975-2927.2.1.1-10 
26. Samad, R., \& Zawawi, F. (2013). Oil Palm Fruit Maturity Grading System using Computer Vision Technique. Malaysian Technical Universities Conference on Engineering \& Technology (MUCET), 1-2.

27. R, A. K., \& Rajpurohit, V. S. (2014). Research Avenues in Fruit Characterization using Machine Vision : A Review. International Journal of Emerging Technology and Advanced Engineering, 4(12), 617-623.

28. Srivastava, P., Ninawe, T., Puthran, C., \& Nirgude, V. (2017). Quadcopter for Rescue Missions and Surveillance. In International conference on computing and virtualization (pp. 48-52).

29. Sawalha, I. H. S. (2015). Managing adversity: understanding some dimensions of organizational resilience. Management Research Review, 38(4), 346-366. http://doi.org/10.1108/MRR-01-2014-0010

30. Goh, H. H., Sim, S. Y., Mohamed, O. A., Mohamed, A. F., Ling, C. W., Chua, Q. S., \& Goh, K. C. (2017). Assessment of power system risk in cyber-attacks in view of the role protection systems. Indonesian Journal of Electrical Engineering and Computer Science, 8(1), 184-191. doi:10.11591/ijeecs.v8.i2.pp184-191

31. Jamil, N., Mohamed, A., \& Abdullah, S. (2009). Automated grading of palm oil Fresh Fruit Bunches (FFB) using neuro-fuzzy technique. In SoCPaR 2009 - Soft Computing and Pattern Recognition (pp. 245-249). http://doi.org/10.1109/SoCPaR.200

\section{AUTHORS PROFILE}

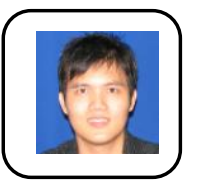

First Author Associate Professor Ts. Dr. GOH Kai Chen is currently Associate Professor, Construction Management of Universiti Tun Hussein Onn Malaysia (UTHM). With a PhD in built environment and engineering, he was awarded as Young Lecturer for the National Blue Ocean Strategy-Joint Initiative Programme (NBOS-PILS) under the Ministry of Higher Education, Malaysia in 2015. Dr. Goh plays active roles in professional bodies. He is the Fellow of ASEAN Academy of Engineering and Technology (FAAET), Professional Technologist (Building \& Construction) under Malaysia board of Technologist, Incorporate member of The Charted Institute of Building, UK and an accredited facilitator of Green Building Index (GBI) Malaysia. His research interests include construction financial management, sustainability, sustainable infrastructure management, life-cycle costing, techno-entrepreneurship, decision support, renewable-energy and construction management.

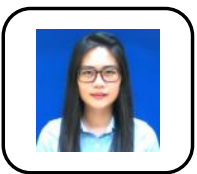

Second Author Dr. Sy Yi Sim received B.Eng. (Hons.) and $\mathrm{PhD}$ degrees in electrical engineering from Universiti Tun Hussein Onn Malaysia, in 2012 and 2016, respectively. She is currently a Lecturer with the Department of Electrical Engineering Technology, Faculty of Engineering Technology, Universiti Tun Hussein Onn Malaysia. Her current research interests include the area of power electronics, motor drives control, renewable energies and artificial intelligence control.

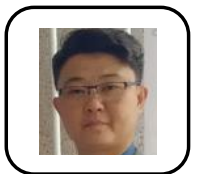

Third Author Dr. Toong Hai Sam received $\mathrm{PhD}$ degrees in Technology Management from Universiti Tun Hussein Onn Malaysia, in 2018, respectively. He is currently a Senior Lecturer with the School of Business, INTI College Nilai, Selangor, Malaysia. His current research interests include the area of entrepreneurship, precision agriculture, sustainable agriculture and system management.

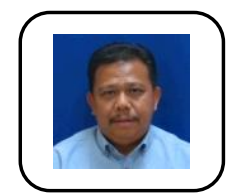

Fourth Author LAr. Dr. Kamalludin bin Bilal is currently Senior Lecturer, Construction Management of Universiti Tun Hussein Onn Malaysia (UTHM). With a $\mathrm{PhD}$ in facility management from Universiti Teknologi Malaysia, Dr. Kamalludin plays active roles in professional bodies. He is the corporate member of Institute Landscape Malaysia, Professional Technologist (Building \& Construction) under Malaysia board of Technologist. His research interests include facility management, sustainability, sustainable infrastructure management, landscape, decision support and construction management.

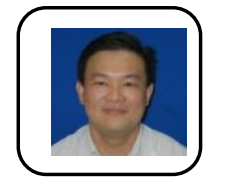

Fifth Author Prof. Ir. Dr. Hui Hwang Goh is currently Professor of School of Electrical Engineering, Guangxi University, Nanning, Guangxi Province, China. Prof. Ir Dr.
Goh plays active roles in professional bodies. He is he is the fellow of Institution of Engineering and Technology (FIET), UK (2016), the fellow of Institution of Engineers, Malaysia (FIEM, 2016), the fellow of ASEAN Academy of Engineering and Technology (FAAET), the Honoree of the Ten Outstanding Young Malaysian by Junior Chamber International in 2014, elected Associate member, Academy Sciences Malaysia since 2016, invited to serve as academic advisory board member to Universities such as UTEM, Swinburne University Sarawak Campus and AIMST University, provide advice to Ministry of Higher Education (MOHE), Ministry of Education (MOE), and many more. His current research interests include the area of power electronics, motor drives control, renewable energies and artificial intelligence control.

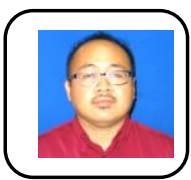

Sixth Author Dr. Sulzakimin Hj Mohamed received Bsc (Hons.) Surveying \& Mapping Sciences from Univ East London UK, Msc Construction Management from Glasgow Caledonian Univ UK and PhD in Technology Management from Universiti Tun Hussein Onn Malaysia, in 1998, 2002 and 2014, respectively. He is currently a Lecturer with the Department of Construction Management, Faculty of Technology Management \& Business, Universiti Tun Hussein Onn Malaysia. His current research interests include the area sustainable development, environment, renewable energies and local government 